\section{"Caiu na rede, é peixe!": a industrialização tardia e suas implicações sobre o trabalho, o ambiente e a saúde no Estado do Ceará, Brasil}

\author{
"Get it while you can!" attitude: late \\ industrialization and implications for work, \\ environment, and health in Ceará State, Brazil
}

Raquel Maria Rigotto 1

\section{Introdução}

The present study focuses on the characteristics of late industrialization in a city in Ceará State (in the semiarid region of Northeast Brazil) and its implications for work, environment, and health in the context of industrial mobility and advanced capitalism. Using direct observation of work processes, interviews (with production managers, company presidents, workers, local authorities, and community leaders), institutional visits and secondary data analysis, eight recently built factories that manufacture chemicals, shoes, electric appliances, clothing, mechanical parts, and packaging were analyzed as to relocation, technology, organization, work relations, worker profile, environmental and occupational risks, and the impact of these factors on health and regulatory mechanisms. The lack of adequate criteria for attracting and accepting new investments, leading to a "get it while you can" attitude, the poor quality of jobs and environmental conditions, and the scale of new changes and risks in the area, like the difficulties of the public sector and society in dealing with these challenges, raise the issue of sustainability in the current development processes.

Industrilization; Environment; Work; Occupational Risks; Working Conditions
Para atender aos novos desafios da competitividade num mercado mundializado, as empresas têm buscado diferentes caminhos de reestruturação de suas estratégias produtivas. Algumas mantêm sua localização e procuram formas de adaptação ágil a conjunturas colocadas pela dinâmica do mercado; para isso investem em tecnologias microeletrônicas, de informática e comunicação e/ou conformam estruturas empresariais mais descentralizadas e integradas, que lhes permitam reduzir gastos com obrigações sociais, inclusive através da terceirização e do trabalho domiciliar. Outras optam por mudar a localização e a organização espacial da empresa, situando suas atividades de forma a beneficiar-se de vantagens locacionais como disponibilidade, custo e perfil de qualificação da força de trabalho; oferta e preço da terra; exigências legais; recursos tecnológicos e de infra-estrutura necessários 1,2,3,4.

Convivem, na mundialização, sociedade industrial e sociedade da informação e do conhecimento. É neste contexto que alguns setores industriais estão se re-localizando em espaços como o Estado do Ceará, no Nordeste do Brasil, a partir dos anos 90: são 624 empresas atraídas entre 1995 e 2000, distribuídas por cerca de um terço dos 184 municípios do estado 5 .

Em cada cidade aonde chegam, as novas indústrias são anunciadas e saudadas como o ad- 
vento do "progresso". A promessa é muito clara - geração de emprego e renda para uma população que vive em pobreza - e comumente bem aceita por gestores públicos e população, pela força da associação simbólica industrializaçãodesenvolvimento.

Mas, como está se dando o encontro destas novas indústrias com as cidades? Quais as contribuições desta política industrial para o desenvolvimento local? Quais os impactos destes processos produtivos sobre a qualidade de vida e sobre o processo saúde-doença?

O propósito deste artigo é justamente examinar as características deste processo de industrialização tardia, analisando suas implicações para o trabalho, a saúde e o ambiente. Trata-se de um recorte nos resultados de pesquisa realizada em Maranguape, a $27 \mathrm{~km}$ da capital do Ceará, Fortaleza. O município tem cerca de 80 mil habitantes, completou agora 150 anos e tem relevantes características ambientais, por estar situado em região semi-árida, mas abrigar também uma serra coberta por Mata Atlântica. Até meados dos anos 90, o município vivia de uma economia agropecuária, artesanal e de pequeno comércio urbano. A partir de 1995, Maranguape recebeu 18 novas indústrias, acolhidas e incentivadas pelo Programa de Promoção e Incentivo à Atividade Industrial (PIAI), implementado pelo estado; e pelas articulações de lideranças políticas locais, que interpretaram ser esta a saída para a crise econômica resultante da retração da atividade agrícola no município, para o desemprego, e para os anseios da população por melhores condições de vida.

A metodologia da pesquisa envolveu o estudo dos processos de trabalho nas indústrias, constando de observação direta do mesmo, a partir de roteiro específico, e de coleta de informações com gerentes e técnicos; da coleta de dados secundários; de entrevistas semi-estruturadas com trabalhadores (em seu domicílio), presidentes das empresas, gestores públicos e entidades de organização da sociedade civil; e de visitas a instituições públicas responsáveis pelas políticas de saúde, trabalho e ambiente.

Na primeira parte do texto são apresentadas as características das empresas e dos trabalhadores. A segunda parte enfoca os processos de trabalho, seus riscos ocupacionais e ambientais e possíveis impactos sobre a saúde, bem como as possibilidades e limites dos mecanismos regulatórios implementados. Estes aspectos são comentados nas perspectivas dos quatro segmentos de atores sociais entrevistados, para considerar, ao final, quem de fato "caiu na rede": as empresas ou o local?

\section{E o "progresso" chegou: as novas indústrias e as relações de trabalho}

Entre as 12 indústrias ainda em funcionamento em setembro de 2001, que geravam 4.167 novos empregos 6, oito foram incluídas no grupo estudado: indústrias metal-mecânica, química, de eletrodomésticos, de calçados, de embalagens plásticas, de confecção de roupas e de confecção de roupas íntimas - por terem concordado com a realização da pesquisa; e a antiga fábrica de colchas, por ser uma empresa originária de Maranguape, permitindo um contraponto importante.

Observa-se que as sete novas indústrias chegaram entre 1995 e 1999, sendo que quatro delas vieram de outros estados: a de calçados e a química, do Rio Grande do Sul; e a de eletrodomésticos e a confecção de roupas íntimas, de São Paulo. As gaúchas vieram num movimento de expansão de suas unidades, e as paulistas estavam transferindo toda a produção para Maranguape, deixando na matriz apenas atividades como criação, vendas, laboratório tecnológico. Também a fábrica de embalagens plásticas, instalada por duas décadas na vizinha Fortaleza, transferiu toda sua produção para Maranguape, em busca das isenções e incentivos fiscais. Veio ainda de Fortaleza a confecção de roupas jeans, que executa apenas as operações mais simples de costura e montagem no processo produtivo. Finalmente, a indústria metal-mecânica, que produz gabinetes metálicos para computadores, é uma empresa nova, cujos proprietários, residentes na capital, optaram por Maranguape para instalá-la.

Além dos incentivos fiscais (redução de $75 \%$ do ICMS devido por período de 10-15 anos) e de outras facilidades - isenção de ISS e de IPTU, cessão de galpões para abrigar a indústria, doação de terrenos para construção, infra-estrutura de serviços -, a oferta abundante de mão-de-obra, com perfil adequado às atividades foi também elemento importante na escolha de Maranguape: "Foi a mão-de-obra, né? Hoje nós temos bastante mão-de-obra aqui. Uma pesquisa também que foi feita no Nordeste sobre mão-de-obra, porque é uma mão-de-obra muito artesanal, e é muito fácil de aprender, porque o calçado é muito artesanal. E a mão-de-obra realmente é muito fácil hoje, e é muito fácil porque aqui o pessoal é muito artesão. Foi uma escolha então aqui no Nordeste" (Superintendente da indústria de calçados em Maranguape).

Todas as empresas declararam ter seus empregados celetistas contratados com carteira assinada. Mas lançam mão também de outros regimes de trabalho. A indústria de eletrodomésticos rotineiramente dobra seu contingente de empregados no segundo semestre do ano, contratando 
trabalhadores por tempo determinado, através de outra empresa: "ficam seis meses e são demitidos", esclareceu o técnico de segurança.

A indústria de calçados e a de confecção de roupas íntimas usam a modalidade de facção: algumas etapas do processo de produção são transferidas a uma micro-empresa, ou mesmo a uma pessoa física, que executa o trabalho através de empregados formais, informais ou de pessoas que trabalham em casa, pagas por peça produzida e aprovada em sua qualidade. Na fábrica de calçados, esta modalidade é adotada para fazer operações que não requerem máquina nem esteira, como explica o chefe do departamento de recursos humanos da indústria de calçados: " $\mathrm{Fa}$ zem em casa mesmo, assistindo televisão. A pessoa vem aqui, pega 200 ou 500 pares [de sapatos], $e$ entrega feito. A empresa dá o material e paga $R \$$ 0,20 a $R \$$ 0,80 por par, dependendo da operação [0 que corresponde a 0,06 e 0,26 centavos de dólar, respectivamente]. Tudo isto varia com a moda. Tem 8 ou 10 grupos [de faccionistas], mas estas pessoas só fazem levar, e lá sim outras pessoas fazem" (Chefe de recursos humanos da indústria de calçados).

Este trabalho, freqüentemente realizado por mulheres, muitas vezes envolve também seus filhos.

As oito empresas estudadas empregavam, no momento da pesquisa, aproximadamente 3.500 trabalhadores, dos quais mais de dois terços são mulheres. A elas são destinados os postos com tarefas manuais que requerem destreza, rapidez e capacidade para executar um trabalho minucioso e monótono.

“As mulheres são mais habilidosas (...) Então, de costura, que vai mais gente, preparação, tudo é mulher. Botar um homem para costurar (...) Dificilmente, né? Não tem o jeito. Pro homem não dá, por causa da idade, não dá pra costurar" (Superintendente da indústria de calçados).

Naquelas em que houve inovação tecnológica, as mulheres permanecem nos postos desqualificados pela automação, ou difíceis ou dispendiosos para automatizar: como revela Hirata 7 , os homens se apropriaram da tecnologia como domínio masculino, paralelamente à construção social do feminino como incompetente tecnologicamente. Por outro lado, a observação dos postos de trabalho reservados aos trabalhadores do sexo masculino revela o outro lado da divisão sexual do trabalho: quando não são "promovidos" aos postos de trabalho complexificados pela automação, eles ficam com as máquinas e funções mais perigosas ou que exigem mais força.

A maioria massiva dos trabalhadores, particularmente da produção, é procedente da própria cidade e está tendo acesso ao decantado "primeiro emprego", a despeito de sua inexperiência industrial e da escolaridade considerada baixa, já que a grande maioria não chegou a concluir o primeiro grau. Chama a atenção a forte concentração de trabalhadores muito jovens: todas as empresas, com exceção da de confecção de colchas, têm a maioria de seus empregados com menos de 30 anos. Em três delas, a faixa etária concentra-se entre 19 e 21 anos, incluindo a maior empregadora - a indústria de calçados, cujo contingente de 2.500 empregados tem média de 22 anos de idade. O sentido desta escolha é muito claro, segundo o chefe do seu departamento de recursos humanos: "é melhor porque não têm vício de outra empresa. A empresa gosta, porque ela faz o funcionário como quer" (grifos meus). De forma ambivalente, a falta de experiência industrial anterior e a baixa escolaridade são usadas no discurso empresarial para desqualificar os trabalhadores e justificar os baixos salários.

"Muitas pessoas acham que está explorando. Mas se colocar uma faixa 'precisa-se de modelador', não encontra. Quando a pessoa conhece é que exige. Aqui em Maranguape é muito difícil falar em campanha salarial. A maioria do pessoal não tem sindicato. Quem tem sindicato é o salário mínimo e mais alguma coisa. É muito difícil porque a maioria é primeiro emprego, é pra aprender. Porque indústria de calçados no Ceará é coisa nova, o pessoal que tá lá nunca viu uma máquina" (Presidente do Sindicato dos Trabalhadores na indústria de calçados; grifos meus).

Por outro lado, outras empresas demonstram forte insatisfação com o perfil do trabalhador cearense: "Cospem no chão, não usam a lixeira, avisam que vão ficar doentes na segunda-feira, não sabem ocupar o tempo que sobra para limpar e organizar (...) Como eles operam desde a matéria-prima até o balde [de tinta], não consigo adestrar, tenho que treinar. Todos começam limpando e pintando, para aprender a não sujar o chão e as paredes. Acham que estou exigindo demais, que é escravidão (...) Nas empresas do sul esta dificuldade é bem menor. Aqui, têm medo da responsabilidade" (Gerente de produção da indústria química; grifos meus).

Entretanto, a percepção do Coordenador da União das Entidades Comunitárias de Maranguape é diferente: "A relação capital-trabalho, ela chega a ter características quase feudais, né? É verdade! O que nós temos visto tem sido o total desrespeito à vida humana, através da exploração sem limites a essa mão-de-obra, que é uma mão-de-obra muito barata, com a desculpa de que é desqualificada. Mas os indicadores de produtividade não confirmam essa desqualificação dessa mão-de-obra!" (grifos meus). 
De fato, também o custo da mão-de-obra foi um atrativo importante para estas indústrias. A remuneração dos trabalhadores em Maranguape é nitidamente inferior à de seus colegas nos municípios de origem das empresas estudadas. Em todos os segmentos industriais, observa-se na cidade o predomínio absoluto da faixa salarial entre 1,01 e 1,5 salários mínimos, à exceção da indústria de colchas, onde prevalece a faixa de 1,51 a 2 salários mínimos. A diferença é muito acentuada na indústria de confecção de roupas íntimas e na de eletrodomésticos, em que a faixa salarial de 1,01 e 1,5 salários mínimos inexiste ou é inexpressiva nas empresas destes segmentos situadas em São Paulo e Itapevi, Estado de São Paulo, respectivamente, cabendo a maior freqüência para a faixa 2,01 a 3 salários mínimos em ambas, e com um perfil mais diversificado nas demais faixas. Os trabalhadores entrevistados têm consciência disto: "Aqui, porque tem muita gente pra trabalhar, é bom pra eles” (Yara, eletrodomésticos; grifos meus).

"Acho que foi pela cidade ser pequena, por muita gente desempregada, a mão-de-obra barata, não paga imposto (...) Tudo isso! Porque aqui não tinha concorrência, aqui não tinha fábrica, tinha muita gente desempregada. Já ouvi falar que lá [no sul] é cem por cento mais, que eles ganham muito mais que a gente, muito mais! Eles vieram descontar de nós..." (Juciene, calçados; grifos meus).

A jornada de trabalho é de 44 horas semanais em todas as empresas, à exceção da de colchas, com jornada de 40 horas, e da indústria de embalagens plásticas, que faz rotineiramente cinco horas e meia de trabalho extra por semana. Três empresas organizam seu trabalho em dois ou três turnos, envolvendo trabalho noturno - o que tem repercussões negativas sobre a saúde dos trabalhadores. Quatro empresas informaram fazer horas-extras: a de eletrodomésticos, a de embalagens plásticas e a metal-mecânica e a química. A de confecção de roupas usa das horas extras raramente e na de colchas não são realizadas horas-extras.

Outras duas empresas utilizam-se de um artifício para estender a jornada de trabalho sem remunerá-la como hora-extra: o banco de horas. $\mathrm{Na}$ indústria de calçados, por exemplo, foram concedidas férias coletivas em algumas semanas do mês de janeiro, logo prorrogadas por mais um período porque não havia demanda por produtos, no refluxo comum após a expansão das vendas na época do Natal. Desta forma, "não tem ninguém mais com direito a férias aqui este ano", como explica o informante.

Para o trabalhador, o banco de horas certamente significa, além de redução de ganhos, o constrangimento a estar mais disponível para a empresa, sem poder planejar seu período de férias ou seu final de semana de acordo com a própria conveniência. De fato, pesquisa sobre o setor coureiro-calçadista conduzida por pesquisadores do Instituto de Pesquisa Econômica Aplicada (IPEA) 8 indica que a resistência dos trabalhadores ao banco de horas deriva das inconveniências nos arranjos familiares causadas pelos horários flexíveis. O banco de horas, assim como as horas-extras significam ainda, para os trabalhadores, algumas jornadas de trabalho mais extensas - o que está relacionado a maior desgaste físico; a maior tempo de exposição aos riscos ocupacionais, sem que o organismo tenha os intervalos necessários para recuperação; e à maior incidência de acidentes de trabalho. Nestes novos empregos gerados, os trabalhadores recebem "benefícios" como cesta básica, alimentação durante o trabalho e creche, abaixo ou no limiar do mínimo exigido pela legislação.

As relações capital-trabalho são "vendidas" pelo governo estadual como mais uma vantagem comparativa do Ceará:

"Não vou dizer que o fato de os nossos serem sindicatos pacíficos seja determinante para atrair o investidor, mas que ajuda, ajuda! O movimento sindical cearense já é maduro o suficiente para perceber que não deve hostilizar um investidor que está gerando emprego no Estado" (Secretário Estadual de Indústria e Comércio do Ceará, em entrevista a Folha de S. Paulo, em 8 de junho de 1997).

A forma como o Presidente do Sindicato dos Trabalhadores na Indústria de Calçados - “convidado pela empresa" para organizar a entidade representativa dos trabalhadores em suas unidades de Maranguape, Russas e Iguatu - descreve as atividades sindicais é bem elucidativa: "Aqui a gente tem auxílio quando o pessoal casa, tem auxílio quando o menino nasce, quando morre (...) É todos de meio salário. (...) Temos contato direto com a diretoria. Toda semana eu vou lá duas, três vezes: problema de mau trato do contra-mestre com o trabalhador, estas besteiras assim. Trabalhador de primeiro emprego visa muito o direito, mas ele também tem obrigações. Uma empresa dessas tem que ter disciplina!" (grifos meus).

As "besteiras" a que ele se refere são as formas de violência nas relações interpessoais, particularmente na indústria calçadista - referida pela população como "a senzala de Maranguape" -, consignadas em rituais de controle da necessidade de beber água ou ir ao banheiro, e em formas de trato humilhantes: “Eu só fiquei lá [na indústria de calçados] dois meses e quinze dias, porque eu não gostei. Meu primeiro emprego, e as pessoas de lá eram muito brutas. Aí os dois meses que eu 
passei trabalhando lá, foi dois meses de choro, que eu não conseguia dizer nada com ninguém, que eles brigavam comigo sem eu ter feito nada. Lá era uma esteira, e aí a pessoa de trás faz errado e o defeito vinha parar na minha mesa, aí eu que levava a culpa. Eu não gostava de brigar com eles, de dizer nada, eu só fazia chorar. Todo dia eu chorava, todo dia chorava. Aí eu disse pra minha mãe que eu ia pedir as contas, e pedi" (Yara, eletrodomésticos).

Ao comungar de forma tão clara com o que a ideologia dominante quer como consenso, o Sindicato produz e difunde o dissenso. Os trabalhadores não identificam, entre as formações discursivas a que têm acesso, algo que corresponda a seus anseios e insatisfações. Não há um núcleo simbólico conformado no qual eles possam encaixar suas idéias, experiências e sentimentos. Ficam no desamparo.

Os trabalhadores entrevistados registram elementos de uma percepção crítica deste processo, na medida em que demonstram conhecer as motivações que impulsionam as novas indústrias em Maranguape; reconhecem que a geração de emprego foi insuficiente, pois ainda há muitos desempregados; denunciam os baixos níveis salariais; propõem um caminho para equacionar o problema da humilhação no trabalho; esboçam o hiato entre o trabalho desejado e o trabalho possível; evocam a latente falta de identidade e de perspectiva no trabalho, as dores e os gritos do corpo, os impactos sobre o ambiente; ou manifestam a expectativa de um processo de mão dupla, que beneficie as empresas e também a população, seja diretamente, seja através da melhoria das políticas públicas, particularmente de saúde e de educação.

Entretanto, no processo de valorização simbólica de cada um destes elementos, ganha ênfase, com unanimidade, a ampliação do mercado de trabalho e das possibilidades de consumo que as novas indústrias trouxeram. Fica muito evidente a força simbólica do desejo de inclusão social: ter uma carteira de trabalho assinada, exibir uma identidade social de trabalhador, proteger-se da marginalidade, ter salário fixo e poder comprar a crédito, ou divertir-se num forró. Ainda que seja uma "integração fictícia", como nomeia Bourdieu ${ }^{9}$. Este desejo de inclusão leva a uma avaliação positiva da industrialização como desenvolvimento.

Já as lideranças da sociedade civil, inseridas em organizações não-governamentais, avaliam de forma crítica os benefícios da geração de empregos: “... as empresas que vêm, elas só têm esse compromisso [pagar o salário]. Nós não vemos um outro benefício. A gente vê que ela, realmente ela gera uma renda, mas o trabalhador, ele está sendo explorado. Ele está sendo explorado! Ele não tem um salário digno, ele não tem a participação dentro da empresa. Além disso, aquela empresa não paga seus impostos, e tudo (...) E ainda corre o risco que, com quinze anos, terminou aquilo ali, ela corre pra outro município, né?" (Coordenador da Câmara dos Conselhos Populares; grifos meus).

"Do ponto de vista econômico, o impacto é muito pequeno, porque ele gerou salário basicamente, não é? Esse salário serve pra que as pessoas comprem, se alimentem e se endividem - quando você tem um salário fixo todo mês, você cria coragem pra comprar alguma coisa no crediário. Mas, o impacto? Não distribui renda, o impacto na economia do município é muito pequeno. Some-se a isso toda uma política de isenção, né? Acaba que o que poderia ficar como valor agregado pra sociedade, desaparece nas isenções..." (Coordenador da União das Entidades Comunitárias de Maranguape; grifo meu).

E o Prefeito de Maranguape faz também uma avaliação crítica, propondo: “Agora, na questão do trabalho, nós temos que ter revisões, eu acho que temos que ter uma análise mais profunda principalmente na questão social, essa da qualidade do trabalho! Porque eu acho que isso beneficia as empresas que têm seus interesses, tudo bem. Mas que veja os interesses dos trabalhadores! Eu acho que tem os direitos sociais, trabalhistas, certo? Então eu acho que há que se parar, fazer uma avaliação disto, saber a opinião do trabalhador, para que nós possamos realmente atender às $d u$ as partes. (...) Eu acho que eles [os empresários] estão tirando muito proveito aquil" (Prefeito de Maranguape; grifos meus).

\section{Processos de trabalho e riscos ocupacionais e ambientais}

No estudo dos processos de trabalho nas indústrias selecionadas, observou-se um curioso contraste, do ponto de vista do padrão tecnológico: nas oito predominam os equipamentos e máquinas de tecnologia tradicional, mas, em seis delas, depara-se com verdadeiras "ilhas tecnológicas”, consubstanciadas, na grande maioria, por apenas uma máquina que incorpora tecnologia micro-eletrônica e informática. Na indústria metal-mecânica, por exemplo, há uma máquina automatizada importada, em meio a prensas barulhentas, sujas de óleo e operadas por pedal, ameaçando amputar dedos dos trabalhadores. $\mathrm{O}$ mesmo contraste repete-se na indústria de eletrodomésticos, embora nela o número de prensas metálicas e injetoras de plástico automatizadas seja maior. 
$\mathrm{Na}$ indústria química, são o pigmento e o know-how da preparação das tintas que contrastam com os enormes tanques de agitação abastecidos manualmente, destampados e contaminando o entorno com solventes; com o layout desorganizado, os tambores arrastados manualmente com enorme esforço pelos trabalhadores. Na fabricação de roupas íntimas, a máquina de corte do tecido, programada por computador, é o orgulho da empresa, ao lado de células onde as trabalhadoras operam centenas de máquinas de costura tradicionais, tomando choque nos dias de chuva. Na fabricação de jeans, de menor porte, uma pequena máquina de pesponto, também operada por computador, é admirada pela encarregada, quando levanta a capa que a protege do pó gerado por mais de cinqüenta máquinas de costura que lembram nossas avós. Na fábrica de colchas, entre a névoa formada pela poeira de algodão e o enorme ruído gerado por teares muito antigos, distingue-se o piscar das luzes do painel eletrônico de uma máquina que borda o tecido no desenho programado, sonhando com vendas para a Argentina.

Ainda em relação ao padrão tecnológico, observa-se que cinco das oito empresas estudadas realizam algumas etapas de seu processo - principalmente design, compras e marketing - fora de Maranguape: é o caso da indústria de calçados, da confecção de roupas íntimas e da de eletrodomésticos. O pigmento utilizado como matéria prima na indústria química vem da Itália para a unidade da empresa em Novo Hamburgo, Rio Grande do Sul, onde é moído e depois enviado ao Ceará. A confecção de roupas realiza apenas a etapa de costura, sendo o design, corte e acabamento feitos na matriz, em Fortaleza.

Estes são bons exemplos das novas relações da produção com o espaço, no contexto da Mundialização. O quadro encontrado em Maranguape é compatível com o que vem sendo descrito sobre a reestruturação produtiva no Brasil: devido ao custo elevado do investimento na qualificação tecnológica, diferentemente dos países desenvolvidos, esta tem acontecido aqui de forma tímida e parcial. Ressalte-se ainda que, no grupo de indústrias em análise, estão quatro empresas com mão-de-obra intensiva - a de calçados, a têxtil e as duas confecções, onde estão $92 \%$ do total de trabalhadores empregados pelo conjunto das oito empresas. Para estes segmentos industriais, quando se pode contar com amplos contingentes de trabalhadores - constrangidos, pelas condições de vida e pelo limitado horizonte de oportunidades, a aceitar baixos salários - certamente é mais vantajoso se aproveitar disto do que investir capital na reestruturação do padrão tecnológico da produção.
Por outro lado, verifica-se a ampla incorporação aos processos de trabalho de novas formas de organização do trabalho - que não dependem de grandes investimentos. Num quadro geral, todas elas têm como ponto de partida a divisão do trabalho prescrita por Taylor, fragmentando a produção numa série de pequenas tarefas de conteúdo pouco significativo, que se repetem ad infinitum. Agora, buscando contornar os problemas que levaram à crise do modelo taylorista-fordista, produz-se o amálgama entre distintas formas de organização do trabalho, enunciadas em tempos históricos que se distanciam em quase um século: o toyotismo, com elementos da especialização flexível, da qualidade total, do just-in-time, da reengenharia e do teamwork. É uma diacronia que pode ser qualificada como perversa ao reunir, de cada uma, o que tem de mais funcional para garantir o controle e a exploração dos trabalhadores e trabalhadoras. Castoriadis 10 , ao discutir a questão da mercadoria-trabalho, oferece elementos para compreender a importância da organização do trabalho para os objetivos da empresa: o que o empresário vai poder extrair da força de trabalho será o resultado de uma luta que não cessará um segundo durante a jornada de trabalho.

A indústria calçadista, por exemplo, fragmenta a fabricação de um modelo de sapato em 150 a 200 operações - como quer Taylor, cada uma delas executada por um trabalhador submetido ao ritmo da esteira fordista, e que ela espera que seja polivalente, na proposta da especialização flexível, para não ter problemas com o absenteísmo de seus colegas. A flexibilização vai permitir ainda que a empresa conte com o trabalho domiciliar de mulheres e crianças, produzindo a baixo custo os lacinhos e trancinhas que as máquinas não podem fazer. Tudo isto sob os cartazes da Qualidade Total, no intuito de que cada trabalhador introjete a incumbência de controlar seu próprio trabalho, para enxugar os níveis hierárquicos da empresa, como quer a re-engenharia. Nas palavras de Dejours 11 (p. 49), "um sistema diabólico de dominação auto-administrado”, que angustia os/as trabalhadores/as.

"Numa noite a gente tem que fazer mil, mil e quinhentos pares: a esteira não pode parar, a máquina não pode quebrar, ninguém pode adoecer na esteira. Aí, nas esteiras, tem o espaço pra colocar cada sapato: se a gente estiver atrasado, em cada espaço vai existir três, aí a gente vai ter que correr contra o tempo, contra o tempo, até atingir o exigido. É assim. Tem que ir do jeito que for, tem que ir, porque não pode parar. O tempo está correndo, eles não querem perder a freguesia, não sei o que é isso, e é assim!" (Juciene, trabalhadora da indústria de calçados; os grifos correspondem a ênfases em sua fala). 
Examinando a questão dos novos riscos introduzidos no território pelas indústrias, procedemos à sua classificação quanto ao grau de risco ocupacional - com base na Norma Regulamentadora 4 (NR 4) da Portaria no. 3214/78 12; e quanto ao potencial de degradação ambiental, com base na proposta de Torres 13 . Como pode ser visto na Tabela 1, trata-se de indústrias de elevado risco ocupacional: a exceção às indústrias de confecção certamente seria desfeita se a classificação incorporasse os significativos riscos relacionados às formas como o trabalho nelas se organiza, como já apontado. Quanto ao potencial de degradação ambiental, pode-se verificar um perfil diferenciado das empresas selecionadas, sendo que a indústria química apresenta a classificação mais elevada, próxima à máxima, embora seja de pequeno porte; as de confecção e de calçados estão próximas à pontuação mínima, e as demais situam-se num patamar intermediário.

De fato, o estudo do processo de trabalho nestas empresas possibilitou observar que elas introduzem uma ampla variedade de condições de risco de natureza física, química, biológica, ergonômica e também de acidentes no território - os mais próximos das fontes de riscos, e também nocivos à saúde da população, através das emissões sólidas, gasosas e líquidas para o solo, a atmosfera, e para as águas superficiais e subterrâneas -, potencialmente prejudiciais à saúde dos trabalhadores que podem comprometer não só os habitantes de seu entorno, mas também populações que vivem mais distante, pela mobilidade dos riscos e por suas formas de difusão no espaço. Alguns destes riscos apresentam nocividade elevada, como os cancerígenos, os teratogênicos e os inflamáveis. As empresas exercem ainda pressões sobre o ambiente, relacionadas ao consumo de água e energia, à ocupação de solo urbano e às especificidades de sua localização em áreas residenciais ou próximas a recursos naturais, como rios e córregos, açudes, e a própria Mata Atlântica que cobre a Serra de Maranguape. As Tabelas 2 e 3 apresentam exemplos dos riscos ocupacionais e ambientais identificados nas empresas estudadas, correlacionando-os com os danos que podem causar à saúde, de acordo com a literatura científica.

No entanto, a efetiva realização do potencial de riscos gerados pelas indústrias é mediada pelas dinâmicas sociais que constroem, definem e implantam os mecanismos regulatórios de sua relação com o ambiente 14,15. A pesquisa empírica mostrou que os mecanismos regulatórios da relação das indústrias com o ambiente e a saúde (projeto tecnológico e organizacional da empresa, os padrões de segurança e saúde no trabalho e de proteção ambiental; cumprimento das
Tabela 1

Classificação das empresas estudadas de acordo com o grau de risco ocupacional e potencial de degradação ambiental.

\begin{tabular}{lcc}
\hline Indústria & $\begin{array}{c}\text { Grau de risco } \\
\text { ocupacional } \\
(1-4)\end{array}$ & $\begin{array}{c}\text { Potencial de degradação } \\
\text { ambiental } \\
(0-9)\end{array}$ \\
\hline Metal-mecânica & 3 & 6 \\
Química & 3 & 8 \\
Eletrodomésticos & 3 & 6 \\
Calçados & 3 & 1 \\
Embalagens plásticas & 3 & 6 \\
Confecção de roupas íntimas & 2 & 1 \\
Confecção de roupas & 2 & 5 \\
Colchas & 3 & 1 \\
\hline
\end{tabular}

Nota: elaboração própria.

medidas preventivas e monitoramento contínuo de sua eficiência) em Maranguape apresentam limitações graves. Em primeiro lugar, não há critérios para orientar a atração de novos empreendimentos, particularmente ambientais ou de saúde: "Não tem. Isto aí não existe não. Caiu na rede, é peixe!” (Gerente de fomento à indústria, comércio e serviços da Prefeitura de Maranguape; grifos meus).

Em segundo lugar, não há canais de participação do poder local - seja a gestão pública, ou a sociedade civil - nas decisões sobre o tipo, a localização e as condições de operação das novas indústrias no território. Em terceiro lugar, o órgão público estadual responsável pelo licenciamento e pelo monitoramento ambiental confronta-se com sérias dificuldades para cumprir a contento suas atribuições. Em quarto lugar, a política destas novas indústrias vem se pautando pelo cumprimento do mínimo exigido na legislação, quando não o fraudam ou resistem com artifícios. No lugar do desejável compromisso ético, que se refletiria numa postura de responsabilidade social e ambiental, encontramos em várias delas a arrogância do "convidado do governador", que se espanta por ser convidado a cumprir a lei.

"Porque se você for pro confronto, é pior: eles [os empresários] têm armas poderosíssimas. Ameaçam logo: 'Pois então eu vou sair!' Não é fácil, porque os empresários se acham acima das instituições. A verdade é essa: quanto maior a empresa, mais ela faz a chantagem: a chantagem do trabalho!" (Prefeito Municipal; grifos meus).

Em quinto lugar - mas não menos importante - está a ausência do poder público municipal no campo das relações trabalho-ambiente-saú- 
Tabela 2

Exemplos de agravos à saúde relacionados a alguns dos riscos ambientais gerados pelas empresas estudadas.

\begin{tabular}{|c|c|c|c|}
\hline & Riscos ambientais & $\begin{array}{l}\text { Empresas em que } \\
\text { foram encontrados }\end{array}$ & Possíveis alterações de saúde \\
\hline \multirow[t]{4}{*}{$\begin{array}{l}\text { Poluição do ar, } \\
\text { da água e do solo }\end{array}$} & $\begin{array}{l}\text { Fumos e poeiras } \\
\text { de metais pesados }\end{array}$ & $\begin{array}{l}\text { Indústria metal-mecânica; } \\
\text { indústria química; } \\
\text { indústria de eletrodomésticos }\end{array}$ & $\begin{array}{l}\text { Intoxicações sistêmicas; doenças da pele; } \\
\text { doenças respiratórias agudas e crônicas; } \\
\text { cânceres; efeitos sobre a reprodução humana }\end{array}$ \\
\hline & Solventes orgânicos & $\begin{array}{l}\text { Indústria metal-mecânica; } \\
\text { indústria química; } \\
\text { indústria de eletrodomésticos }\end{array}$ & $\begin{array}{l}\text { Encefalopatia tóxica crônica; transtorno } \\
\text { cognitivo leve; transtornos de personalidade } \\
\text { e de comportamento; episódios depressivos; } \\
\text { neurastenia; hipoacusia ototóxica; } \\
\text { polineuropatia; doenças respiratórias } \\
\text { agudas; dermatite alérgica de contato; } \\
\text { dermatite de contato por irritantes; cânceres; } \\
\text { efeitos sobre a reprodução humana }\end{array}$ \\
\hline & $\begin{array}{l}\text { Poluição (do solo) por borras, } \\
\text { lodos, estopas, embalagens } \\
\text { de produtos químicos e } \\
\text { resíduos sólidos }\end{array}$ & $\begin{array}{l}\text { Indústria metal-mecânica; } \\
\text { indústria química; indústria } \\
\text { de eletrodomésticos; } \\
\text { indústria de calçados }\end{array}$ & $\begin{array}{l}\text { Intoxicações sistêmicas; cânceres; } \\
\text { efeitos sobre a reprodução humana }\end{array}$ \\
\hline & $\begin{array}{l}\text { Microrganismos, insetos } \\
\text { e roedores }\end{array}$ & Indústria de embalagens & Doenças infecto-parasitárias \\
\hline \multirow{2}{*}{$\begin{array}{l}\text { Consumo elevado } \\
\text { de recursos naturais }\end{array}$} & Água & Indústria têxtil & Efeitos indiretos da escassez de água \\
\hline & Energia elétrica & $\begin{array}{l}\text { Indústria de calçados; indústria } \\
\text { de eletrodomésticos }\end{array}$ & $\begin{array}{l}\text { Efeitos indiretos da pressão sobre a matriz } \\
\text { energética (barragens, termoelétricas etc.) }\end{array}$ \\
\hline \multirow[t]{2}{*}{ Acidentes ampliados } & $\begin{array}{l}\text { Solventes inflamáveis (incêndios } \\
\text { e lançamentos acidentais) }\end{array}$ & $\begin{array}{l}\text { Indústria química; } \\
\text { indústria de calçados }\end{array}$ & $\begin{array}{l}\text { Queimaduras; irritação de vias aéreas } \\
\text { superiores; encefalopatia tóxica aguda }\end{array}$ \\
\hline & $\begin{array}{l}\text { Circulação de veículos } \\
\text { transportadores de carga } \\
\text { tóxica (matérias-primas, } \\
\text { produtos ou resíduos) }\end{array}$ & $\begin{array}{l}\text { Indústria química; indústria de } \\
\text { calçados; indústria têxtil; } \\
\text { indústria de eletrodomésticos }\end{array}$ & $\begin{array}{l}\text { Intoxicações agudas; cânceres; } \\
\text { efeitos sobre a reprodução humana }\end{array}$ \\
\hline Alterações no tráfego & $\begin{array}{l}\text { Geração de tráfego de veículos } \\
\text { de carga e/ou transporte coletivo } \\
\text { de trabalhadores e/ou bicicletas }\end{array}$ & Todas as empresas & $\begin{array}{l}\text { Acidentes de trânsito; doenças respiratórias: } \\
\text { irritação de vias aéreas superiores, asma, } \\
\text { doença pulmonar obstrutiva crônica }\end{array}$ \\
\hline \multirow[t]{2}{*}{$\begin{array}{l}\text { Alterações em fatores } \\
\text { relacionados à } \\
\text { qualidade de vida }\end{array}$} & Geração de ruído & $\begin{array}{l}\text { Indústria metal-mecânica; } \\
\text { indústria têxtil; indústria de } \\
\text { eletrodomésticos; indústria química; } \\
\text { indústria de embalagens }\end{array}$ & Desconforto \\
\hline & Geração de calor & $\begin{array}{l}\text { Indústria metal-mecânica; } \\
\text { indústria têxtil; indústria de } \\
\text { embalagens }\end{array}$ & Desconforto térmico \\
\hline
\end{tabular}

Fonte: elaborada pela autora com base na pesquisa de campo e na literatura científica: World Health Organization 17; International Labour Office 18; Banco do Nordeste 19; Schlesinger 20 
Exemplos de agravos à saúde relacionados a alguns dos riscos ocupacionais encontrados nas empresas estudadas.

\begin{tabular}{|c|c|c|}
\hline Riscos ocupacionais & Empresas em que foram encontrados * & Possíveis alterações de saúde \\
\hline $\begin{array}{l}\text { Prensas operadas por } \\
\text { comando manual }\end{array}$ & $\begin{array}{l}\text { Indústria metal-mecânica; indústria de } \\
\text { eletrodomésticos; indústria de embalagens }\end{array}$ & Corte de mãos e dedos; amputação de dedos \\
\hline $\begin{array}{l}\text { Máquinas com partes } \\
\text { móveis desprotegidas }\end{array}$ & Todas & Cortes e amputações; escalpelo \\
\hline $\begin{array}{l}\text { Instalações elétricas } \\
\text { inadequadas }\end{array}$ & $\begin{array}{l}\text { Indústria química; indústria de } \\
\text { confecção de roupas; indústria de } \\
\text { confecção de oupas íntimas }\end{array}$ & Choque elétrico \\
\hline Inflamáveis e explosivos & $\begin{array}{l}\text { Indústria química; indústria de } \\
\text { eletrodomésticos; indústria de colchas }\end{array}$ & Queimaduras \\
\hline Ruído & Todas & $\begin{array}{l}\text { Perda da audição provocada pelo ruído; outras percepções } \\
\text { auditivas anormais: alteração temporária do limiar auditivo, } \\
\text { comprometimento da discriminação auditiva e hiperacusia; } \\
\text { hipertensão arterial; ruptura traumática do tímpano }\end{array}$ \\
\hline Trabalho noturno & $\begin{array}{l}\text { Indústria química; indústria metal- } \\
\text { mecânica; indústria de; } \\
\text { eletrodomésticos indústria de colchas }\end{array}$ & Transtorno do ciclo vigília-sono \\
\hline $\begin{array}{l}\text { Posições forçadas e } \\
\text { esforços repetitivos }\end{array}$ & Todas, exceto a indústria química & $\begin{array}{l}\text { Transtornos do plexo braquial; síndrome da saída do tórax; } \\
\text { síndrome do desfiladeiro torácico; síndrome do túnel } \\
\text { do carpo; síndrome do pronador redondo; síndrome do } \\
\text { canal de Guyon; síndrome do túnel cubital; lesão do nervo } \\
\text { radial; compressão do nervo supra-escapular; artrose; } \\
\text { síndrome cervico-braquial; sinovites e tenossinovites; } \\
\text { tendinites; lesões do ombro; epicondilites; bursites; } \\
\text { moléstia de Dupuytren; mononeuropatias do membro } \\
\text { inferior; lesão do nervo poplíteo lateral }\end{array}$ \\
\hline Tolueno & Indústria química; indústria de calçados & $\begin{array}{l}\text { Encefalopatia tóxica crônica; transtorno cognitivo leve; } \\
\text { transtornos de personalidade e de comportamento; } \\
\text { episódios depressivos; neurastenia; hipoacusia ototóxica }\end{array}$ \\
\hline Hexano & $\begin{array}{l}\text { Indústria química; indústria de calçados; } \\
\text { indústria de confecção de roupas íntimas }\end{array}$ & Polineuropatia \\
\hline Anilina & Indústria de colchas & Neoplasia maligna da bexiga \\
\hline Ritmo de trabalho penoso & $\begin{array}{l}\text { Indústria de calçados; indústria de } \\
\text { confecção de roupas íntimas }\end{array}$ & $\begin{array}{l}\text { Neurose profissional; síndrome de burnout; síndrome } \\
\text { do esgotamento profissional; dorsalgia; cervicalgia ciática; } \\
\text { lumbago com ciática }\end{array}$ \\
\hline $\begin{array}{l}\text { Solventes, graxas, detergentes, } \\
\text { níquel, cromo, óleos minerais }\end{array}$ & $\begin{array}{l}\text { Em todas as empresas há pelo menos } \\
\text { um deles, exceto na confecção de roupas }\end{array}$ & $\begin{array}{l}\text { Dermatite alérgica de contato; dermatite de contato por } \\
\text { irritantes; elaioconiose (graxas e solventes clorados) }\end{array}$ \\
\hline
\end{tabular}

Fonte: elaborada pela autora com base na pesquisa de campo e na literatura científica: Ministério da Saúde 21.

* Nestas empresas, o número de trabalhadores expostos a estes riscos é variável, não abrangendo, necessariamente, o conjunto dos empregados. 
de: a despeito das atribuições constitucionais e legais, dos problemas já percebidos pelos gestores e registrados em documentos oficiais, não são desenvolvidas ações de vigilância nem dos ambientes de trabalho nem do ambiente em geral. Em sexto lugar, as entidades da sociedade civil estudadas, embora estejam acompanhando o processo e sejam críticas aos impactos sociais, ambientais e de saúde, ainda não pautam este tema em suas agendas políticas ou, como no caso do sindicato de trabalhadores do calçado, compactuam com os interesses da indústria.

Conforma-se assim um cenário em que as novas indústrias podem se sentir quase totalmente à vontade para introduzir novos riscos em Maranguape, face à fragilidade dos mecanismos regulatórios. Neste cenário sócio-político, os riscos são amplificados e potencializados, inclusive em sua nocividade 16. Estão abertos os caminhos para o dumping ambiental e para o adoecimento da população...

A percepção destes riscos ambientais não é freqüente entre os trabalhadores entrevistados este depoimento diferencia-se dos demais: "Muita poluição. Pra onde é que vai aquela cola que sobra, pra onde é que vai aquele couro que sobra? Aqueles saltos, vai pra onde? Vai pro rio? Vai pro lixão? Ninguém sabe pra onde é que vai, né? Você vê que todo dia a camada de ozônio tá cada vez maior, tá cada vez mais quente, tá cada vez mais difícil pra pessoa viver" (Juciene, trabalhadora da indústria de calçados).

Por outro lado, alguns gestores públicos reconhecem a gravidade da situação e a omissão do poder público municipal, ao mesmo tempo em que revelam a disputa de concepções sobre desenvolvimento local no interior da equipe de governo: "Ah! Eu fico muito preocupado, primeiro porque Maranguape não tem nenhuma infraestrutura nessa questão de captação de dejetos. Nem domiciliares, quanto mais de esgoto industrial (...) Então é uma temeridade mesmo você ter essa questão! E aí a gente fica muito preocupado, porque tem uma contaminação contínua desses solventes utilizados, principalmente pelo pólo calçadista, né? Eaífica mais uma pergunta:e quem monitora essa carga contaminante? A gente, por exemplo, na SEMADE [Secretaria de Meio Ambiente e Desenvolvimento], não temos dados sobre isso, né? Eu diria, com toda a sinceridade: essa questão [dos impactos das indústrias sobre o ambiente] é posta num plano que vem logo em seguida, num plano, plano secundário, tá entendendo?" (Gerente do Núcleo de Planejamento em Saúde; grifos meus).

Já os riscos ocupacionais gerados nestes processos produtivos são claramente percebidos pelos trabalhadores, seja na experiência cotidiana de seus corpos no trabalho, seja presenciando acidentes que os deixam chocados: "Justamente eu tava trabalhando nesta máquina, aí quando souberam que eu estava grávida, eles me transferiram pra outra mesa. Aí colocaram uma amiga minha lá, nesta máquina. Aí eu tava assim de costa, tava trabalhando, né? Só ouvi o grito dela! A a gente procurou, era ela. A máquina ficou assim, ela escapou, ela era linhadeira, ela tava perto de mim (...) Aí soltaram, soltaram as mãos e soltaram o botão, aí a máquina desceu e o dedo caiu lá embaixo. Aí a gente ouviu o grito, o meu monitor correu, chegou lá, ela desmaiou na hora, da dor, e viu que ela tava sem os dedos; aí levaram ela pro hospital. Ela tava de luva, aí o médico tirou, tava o dedinho pendurado assim (...) Quebrou o osso dela. Hoje a mão dela é assim, cortou os dedos assim" (Yara, trabalhadora da indústria de eletrodomésticos).

"A fôrma que tava dentro saiu com tanta força, que bateu no rosto dele, que ele caiu! A outra subiu, foi lá em cima e voltou, só foi esbarrar na outra fábrica, distante! Ele passou mais de quinze dias no hospital (...) Ficou sem sentidos. Quase que morre! Pegou no rosto dele assim ó, ele foi olhar e pegou nele assim ó!' (Cacá, trabalhador da indústria de calçados).

"Vários funcionários são atendidos mesmo que diariamente nos hospitais: trabalho com cola, trabalho em galpões muito quentes, então dá aquele desmaio..." (Coordenador da Câmara dos Conselhos Populares).

De fato, dentro das limitações dos dados oficiais disponíveis, verificamos que o período de instalação das novas indústrias repercute-se nas estatísticas oficiais na forma de uma significativa elevação dos acidentes e doenças relacionadas ao trabalho, mas há indícios de que estes dados estejam ainda inferiores ao que realmente está ocorrendo nas fábricas. Em termos de freqüência, estes acidentes consistem em sua maioria em traumatismos, e acometem predominantemente as mulheres, enquanto os homens sofrem os quadros mais graves. Várias das doenças e acidentes que supusemos poderiam estar ocorrendo no município, a partir dos riscos identificados nas empresas estudadas, compareceram entre os quadros mórbidos diagnosticados, ao passo que outros, cuja caracterização demanda maior competência dos serviços de saúde, não foram encontrados.

Agrava este quadro o fato de que ainda não se pode contar com as políticas públicas para cumprir adequadamente sequer a fase das conseqüências dos mecanismos regulatórios da relação indústria-ambiente: diagnosticar e tratar os agravos, amparar os doentes, gerar e divulgar informações fidedignas e de qualidade sobre o 
processo saúde-doença em curso e seus determinantes. Esta é mais uma dimensão das dificuldades para visualizar os impactos do processo de industrialização-urbanização sobre a saúde da população. O sistema de saúde do Estado do Ceará, e também o de Maranguape, ainda é como que "cego" para os agravos à saúde relacionados aos processos produtivos e seus riscos ocupacionais e ambientais. Deliberadamente ou não, isto vem a se constituir enquanto uma estratégia de negação e de ocultamento dos impactos negativos do processo de desenvolvimento em curso no estado sobre a saúde.

\section{Considerações finais}

Entre 1991 e 2000 - a década da industrialização -, o Índice de Desenvolvimento Humano Municipal (IDH-M) atribuído a Maranguape elevou-se de 0,576 para 0,691. Mas esta elevação deveu-se principalmente ao progresso nos indicadores relativos à educação, embora a média de anos de estudo ainda seja baixa (4,1 anos), e o analfabetismo seja ainda uma realidade para $28,8 \%$ da população. O componente longevidade também apresentou evolução positiva neste período, seja pela significativa redução da mortalidade infantil (de 63,9 para 36,0), seja pelo aumento da esperança de vida ao nascer (de 61,2 para 69,2 anos em 2000), acompanhando as tendências demográficas do país.

O componente renda foi o que apresentou o menor desempenho: se a renda per capita passou de R \$ 76,40 em 1991 para R \$ 105,10 em 2000, a proporção de pessoas com renda domiciliar per capita inferior a meio salário mínimo ainda é elevada $(59,2 \%)$. Mais que isto, a desigualdade, medida pelo índice de Gini, cresceu de 0,51 para 0,54 no período. De fato, a despeito dos 4.167 empregos gerados pelas novas indústrias, a proporção da renda apropriada por extratos da população reduziu-se em todos os segmentos, no período considerado, exceto para os $20 \%$ mais ricos, no qual elevou-se de $56,3 \%$ para $57,9 \%$.

Se, na perspectiva de alguns gestores públicos, Maranguape lança sua rede na sociedade mundializada e "é contemplada" com indústrias que se re-localizam, numa perspectiva crítica pode-se ver Maranguape sendo capturada por este imenso território-rede hoje articulado pelo capital. Esta industrialização - exploradora da vitalidade e dos sonhos dos jovens, da necessidade das mulheres-mães que são chefes de família, da fragilidade das instituições públicas responsáveis pelo cuidado com a saúde, o trabalho e o ambiente, e da insipiência da organização da sociedade - é a que cabe a esta cidade do Nordeste do Brasil hoje. É a sua forma de participar da Globalização e da Reestruturação Produtiva; é o seu quinhão na distribuição internacional dos riscos ocupacionais e ambientais.

As novas indústrias poderiam ser vistas como nós desta rede, pequenas incrustações dela no território maranguapense, que chegam a constituir-se enquanto micro-territórios do capital que promovem uma des e uma re-territorialização em Maranguape, mergulhando fundo inclusive no campo da cultura, no sentido que interessa à hegemonia hoje: "Eu fico triste quando eu vou pra determinadas localidades do município de Maranguape, onde a grande novidade é esperar o ônibus da [indústria de calçados]! Quer dizer - pelo amor de Deus, que merda é essa! - que a grande novidade é quando o ônibus da [indústria de calçados] vem pra pegar aqueles jovens?! Isso é triste, sabe? Isso é uma coisa horrivel, né!!?" (Gerente de planejamento em saúde da Prefeitura de Maranguape).

Maranguape capturou as indústrias em sua rede, ou está sendo capturada entre os nós e fluxos da enorme rede do capital contemporâneo? 


\section{Resumo}

São analisadas as características da industrialização tardia, em curso num município do semi-árido cearense, para discutir suas implicações para o trabalho, o ambiente e a saúde, no cenário da mobilidade industrial no capitalismo avançado. Com base na observação direta dos processos de trabalho; entrevistas com gerentes de produção e presidentes de empresas, trabalhadores, gestores públicos e lideranças da sociedade civil; visitas institucionais e análise de dados secundários, caracterizaram-se oito empresas dos setores químico, calçadista, eletrodoméstico, confecção, metal-mecânico e embalagens, recém instaladas em Maranguape, Ceará, Brasil, no tocante às circunstâncias de sua re-localização; tecnologia, organização e relações de trabalho; perfil dos trabalhadores; riscos ocupacionais e ambientais gerados, seus impactos sobre a saúde e os mecanismos regulatórios. A falta de critérios na atração e aceitação destes investimentos - “caiu na rede, é peixe!", a precária qualidade do emprego e das condições ambientais geradas, a magnitude das transformações promovidas no território e dos riscos nele introduzidos, assim como a fragilidade do Estado e da sociedade para lidar com eles, levantam questionamentos sobre a sustentabilidade destes processos de desenvolvimento.

Industrialização; Meio Ambiente; Trabalho; Riscos Ocupacionais; Condições de Trabalho

\section{Referências}

1. Rattner H. Globalização: em direção a um mundo só? In: Becker B, Miranda M, organizadores. A geografia política do desenvolvimento sustentável. Rio de Janeiro: Editora UFRJ; 1997. p. 127-48.

2. Rubio MV. La industria urbana: de la obsolescencia a la innovación. In: Universidad de Alicante/Asociación de Geógrafos Españoles, organizadores. Industria y medio ambiente. Alicante: Universidad de Alicante/Asociación de Geógrafos Españoles; 2000. p. 15-33.

3. Castleman B. The migration of industrial hazards. Int J Occup Environ Health 1995, 1:85-96.

4. Alió MA. Tendencias y protagonistas de las políticas ambientales: aportaciones a la teoría del cambio hacia la prevención de los residuos. In: Universidad de Alicante/Asociación de Geógrafos Españoles, organizadores. Industria y medio ambiente. Alicante: Universidad de Alicante/Asociación de Geógrafos Españoles; 2000. p. 299-313.

\section{Agradecimentos}

Pesquisa parcialmente apoiada com recursos da Coordenação de Aperfeiçoamento de Pessoal de Nível Superior (CAPES; processo BEX0238/02-3).
5. Governo do Estado do Ceará. Programa de atração de investimentos. Fortaleza: Secretaria de Desenvolvimento Econômico; 2000.

6. Instituto de Desenvolvimento do Trabalho. Aspectos demográficos e conjunturais do mercado de trabalho - Maranguape. Relatório de pesquisa. Fortaleza: Instituto de Desenvolvimento do Trabalho; 2002.

7. Hirata H. Nova divisão sexual do trabalho? Um olhar voltado para a empresa e a sociedade. São Paulo: Boitempo Editorial; 2002.

8. Noronha EG, Turchi LM. Cooperação e conflito: estudo de caso do complexo coureiro-calçadista no Brasil. Brasília: Instituto de Pesquisa Econômica Aplicada; 2002. (Texto para Discussão, 861).

9. Bourdieu P. O poder simbólico. 2a Ed. Rio de Janeiro: Bertrand Brasil; 1998.

10. Castoriadis C. A experiência do movimento operário. São Paulo: Editora Brasiliense; 1985. 
11. Dejours C. A banalização da injustiça social. Rio de Janeiro: Fundação Getúlio Vargas; 1999.

12. Ministério do Trabalho. Portaria 3.214 de 8 de junho de 1978. Aprova as normas regulamentadoras do capítulo V do título II da Consolidação das Leis do Trabalho, relativas à segurança e medicina do trabalho. Diário Oficial da União 1978; 9 jun.

13. Torres $\mathrm{H}$. Indústrias sujas e intensivas em recursos naturais: importância crescente no cenário industrial brasileiro. In: Martine G, organizadora. População, meio ambiente e desenvolvimento: verdades e contradições. 2a Ed. Campinas: Editora Unicamp; 1996. p. 43-68.

14. Porto MFS. Trabalho industrial, saúde e ecologia: avaliação qualitativa de riscos industriais, com dois estudos de caso na indústria química [Tese de Doutorado]. Rio de Janeiro: Instituto Alberto Luiz Coimbra de Pós-graduação e Pesquisa de Engenharia, Universidade Federal do Rio de Janeiro; 1994.

15. Porto MFS. Considerações sobre a dinâmica de regulação dos riscos industriais e a vulnerabilidade da sociedade brasileira. In: Herculano S, Porto MFS, Freitas CM, organizadores. Qualidade de vida e riscos ambientais. Niterói: EdUFF; 2000. p. 147-70.
16. Porto M, Freitas C. Socio-political amplification of chemical accidents in industrializing countries. Risk Anal 1996; 16:19-29.

17. World Health Organization. Report of the panel on industry. Geneva: World Health Organization; 1992.

18. International Labour Office. Encyclopedia of occupational health and safety. $4^{\text {th }}$ Ed. Geneva: International Labour Office; 1998.

19. Banco do Nordeste. Manual de impactos ambientais: orientações básicas sobre aspectos ambientais de atividades produtivas. Fortaleza: Banco do Nordeste; 1999.

20. Schlesinger S. Indústria no Brasil: produção sustentável, consumo democrático. Rio de Janeiro: FASE; 2001.

21. Ministério da Saúde. Doenças relacionadas ao trabalho: manual de procedimentos para os serviços de saúde. Brasília: Ministério da Saúde; 2000.

Recebido em 02/Mai/2006

Versão final reapresentada em 06/Fev/2007

Aprovado em 27/Fev/2007 